\title{
New species of Rhabdias (Nematoda: Rhabdiasidae) from Afrotropical anurans, including molecular evidence and notes on biology
}

\author{
Kerstin Junker ${ }^{1}$, Nathaly Lhermitte-Vallarino ${ }^{2}$, Michela Barbuto ${ }^{3}$, Ivan Ineich ${ }^{4}$, Samuel Wanji and Odile Bain $^{2}$ \\ ${ }^{1}$ Department of Veterinary Tropical Diseases, University of Pretoria, Private Bag X04, Onderstepoort, 0110, South Africa; \\ Current address: Onderstepoort Veterinary Institute, Private Bag X05, Onderstepoort, 0110, South Africa; \\ ${ }^{2}$ Muséum National d'Histoire Naturelle, UMR 7205 CNRS, Origine, Structure et Evolution de la Biodiversité, Parasitologie com- \\ parée, CP52, 61 rue Buffon, 75231 Paris cedex 05, France; \\ ${ }^{3}$ Università degli Studi Milano Bicocca, Dipartimento di Biotecnologie e Bioscienze, Piazza della Scienza 2, 20126 Milano, Italy; \\ ${ }^{4}$ Muséum National d'Histoire Naturelle, UMR 7205, Origine, Structure et Evolution de la Biodiversité, Section Reptiles, Taxon- \\ omie et Collections, CP 30, 25 rue Cuvier, 75005 Paris, France; \\ ${ }^{5}$ Research Foundation for Tropical Diseases and the Environment, P.O. Box 474, Buea, Cameroon
}

\begin{abstract}
Despite the small sample size the diversity of Rhabdias Stiles et Hassall, 1905 from anurans in the Afrotropical region was found to be high. Four species were collected from four localities, one in South Africa, two on Cameroonese mountains and one in Madagascar: Rhabdias picardiae sp. n. from the bufonid Amietophrynus gutturalis (Power); Rhabdias ohlerae sp. n. and Rhabdias tanyai sp. n. from the arthroleptids Leptopelis brevirostris (Werner) and Astylosternus rheophilus Amiet, respectively; and Rhabdias vencesi sp. $\mathrm{n}$. from the mantellid Boophis madagascariensis (Peters). Distinctive characters between these species are numerous and obvious, based on body size, shape and size of the buccal capsule, arrangement of head papillae, and shape and size of the oesophagus and intestinal apex. Molecular data based on $500 \mathrm{bp}$ of $12 \mathrm{~S} \mathrm{rDNA}$ and $600 \mathrm{bp}$ of coxI of three of the four species are presented. Rhabdias vencesi resembles Rhabdias madagascariensis Chabaud, Brygoo et Petter, 1961 from an African ptychadenid introduced on Madagascar, but differs in body size and head morphology. The remaining new species are clearly distinct from those previously known from Afrotropical anurans. Outside the Afrotropics, some Rhabdias species present characters similar to those observed in the new species, but they all differ in various other characters. No clear correlation was seen between Rhabdias species and families of anuran hosts in this region. However, the narrow buccal capsule seen in Rhabdias species from Afrotropical lissamphibians opposes them to the majority of Rhabdias parasitic in chamaeleonids. Furthermore, the infective larva of $R$. vencesi has a conical pointed tail, while those of Rhabdias from chameleons have a rounded tail tip ornated with a few buds.
\end{abstract}

Keywords: parasitic nematodes, Rhabdias, molecular characterisation, taxonomy, anurans, Amietophrynus, Astylosternus, Boophis, Leptopelis, Afrotropical region

Of the 39 species of Rhabdias Stiles et Hassall, 1905 parasitising anuran hosts (Baker 1987a, Bursey et al. 2003, Kuzmin et al. 2007, Martínez-Salazar and LeónRègagnon 2007, Martínez-Salazar 2008, Kuzmin and Tkach 2009), only three have been described in the Afrotropical region, one from Ptychadenidae in Madagascar (Chabaud et al. 1961), another from Arthroleptidae in Tanzania (Baker 1987b) and a third from two members of Bufonidae in South Africa (Kuzmin 2001). Close to this region, in Egypt, Rhabdias was reported from a bufonid with a sub-Saharan distribution, the parasites being either assigned to a European species (Moravec et al. 1987), or left unnamed (Saad et al. 2009). A fifth Rhabdias species (Baylis 1929) is a parasite of Gymnophiona, a small group of lissamphibians.
Recently, renewed interest in the diversity of Rhabdias in the Afrotropical region led to detailed studies concentrating on hosts belonging to the Chamaeleonidae, a group of saurian hosts found to harbour a wide variety of lung worm species (Lhermitte-Vallarino and Bain 2004, Lhermitte-Vallarino et al. 2008, 2009a, b).

During the past two years, lung worms were recovered from four species of Afrotropical anurans belonging to the Bufonidae, Arthroleptidae and Mantellidae. Morphological analysis of their Rhabdias fauna suggested the presence of a distinct and new species in each of the four hosts. In this paper, we give a morphological description of the new taxa and provide a molecular characterisation based on the 12S rDNA and mitochondrial cytochrome $c$ oxidase subunit 1 (coxl) genes of three of the four species.

Address for correspondence: O. Bain, Muséum National d'Histoire Naturelle, UMR 7205 CNRS, Origine, Structure et Evolution de la Biodiversité, 61 rue Buffon, CP52, 75231 Paris cedex 05, France. Phone: +33 (0)1 40793497; Fax: +33 (0)1 40793499; E-mail: bain@mnhn.fr 
In order to assess the mode of reproduction, the genital tracts of the parasitic females of each species were examined as in previous studies (Lhermitte-Vallarino and Bain 2004, Lhermitte-Vallarino et al. 2008, 2009a, b). Free-living stages of one of the species were obtained through faecal culture and their development and morphology described. The aim of this study was not only to estimate Rhabdias diversity among lissamphibians in the Afrotropical region, but to collect additional information on species from this host group to elucidate their relationship with parasites from chamaeleonids.

\section{MATERIALS AND METHODS}

The hosts. The nomenclature of amphibian hosts follows that of Frost (2009). Frost et al. (2006) placed former members of the genus Bufo Laurenti (Bufonidae) in several genera, amongst others Bufo, Rhinella Fitzinger, Amietophrynus and Duttaphrynus, the latter two named by Frost et al. (2006); at the same time, several species were synonymized. In order to facilitate comparison with existing literature reports, the new and previous names are given here, as well as in the taxonomic discussions. Bufo americanus Holbrook is now listed as Anaxyrus americanus (Holbrook), Bu. garmani Meek, Bu. gutturalis Power, Bu. regularis Reuss and Bu. maculatus Hallowell have been placed into the genus Amietophrynus, and Bu. melanostictus Schneider is now listed as Du. melanostictus (Schneider) (Frost 2009). Kloss (1971) recorded 'Bufo typhonius (L.)' from Belém, Pará, Brazil, as the type host of $R$. androgyna Kloss, 1971, but Frost et al. (2006) have subsequently split the $B u$. typhonius complex into several genera and species. Given the geographic distribution of Kloss' (1971) specimens, it would seem most likely that his material belonged to what is currently known as Rh. margaritifera (Laurenti), a common South American toad occurring throughout Amazonian South America and eastern Panama (Frost 2009). Similarly, Travassos (1926) described R. fülleborni Travassos, 1926 from 'Bufo marinus L.' from Brazil. However, several subspecies of the Bu. marinus complex have been synonymized and placed into different species within the genus Rhinella. Since Travassos (1926) listed Linnaeus as host authority, it appears most likely that he was referring to a host now listed as Rh. marina (Linnaeus) by Frost (2009). To avoid confusion, host genera are abbreviated using the first two letters of the generic name.

In September 2008, the lungs of five Am. gutturalis from South Africa were examined for the presence of Rhabdias by one of the authors (K.J.; no permit required). Several worms were recovered, fixed and stored in absolute ethanol. Two Boophis madagascariensis (Peters) (Mantellidae), imports from Madagascar, were necropsied; worms were fixed in hot $70 \%$ ethanol, except for two that were transferred directly into absolute ethanol for molecular analysis.

The remaining material was collected in Cameroon by N. L.-V. and I.I., while collaborating on a biodiversity project in this region (Lhermitte-Vallarino et al. 2008). Two arthroleptid species were captured on two distinct mountains in the Cameroonese volcanic chain, a single Leptopelis brevirostris (Werner) from Mount Cameroon and a single Astylosternus rheophilus Amiet from Mount Oku. Each frog harboured a single lung worm. The specimen from As. rheophilus was drawn alive un- der a stereomicroscope. Subsequently, a part of its mid-section was removed and fixed directly in absolute ethanol for molecular analysis. Both the anterior and posterior parts were fixed in hot $70 \%$ ethanol. The collection and exportation of specimens had been authorized by the Cameroon Ministry of Forests and Fauna. Hosts from Cameroon and Madagascar are kept in the National Collection of the Muséum National d'Histoire Naturelle (MNHN), Paris. Anurans from Cameroon were identified by A.M. Ohler, MNHN.

Morphological analysis. Specimens were cleared in lactophenol and observed under a compound microscope equipped with a drawing tube. Measurements were taken from drawings and are given in micrometres unless otherwise stated. Width of buccal capsule corresponds to its maximum external diameter, and buccal capsule length excludes the more or less distinct granulous posterior segment as described in Lhermitte-Vallarino et al. (2009b). Based on previous studies (Tkach et al. 2006, Lhermitte-Vallarino et al. 2008, Martínez-Salazar 2008), four ratios are provided: percentage of oesophagus length and tail length of total body length (TBL), distance from apex to vulva as percentage of TBL, and buccal capsule ratio (buccal capsule length/buccal capsule width). Two measurements regarding body width are given, the first indicating body width excluding the vesicle followed by the one including it in parentheses. Presented in the text is the type-series range of measurements for each morphological character. Individual measurements of the holotype and paratypes are listed in Tables 1-3. Ovaries were examined for the presence of a male gamete production area, named testis zone, according to Runey et al. (1978).

Molecular analysis. Specimens analysed in this study were stored in accordance with procedures specified in the Biorepositories initiative (http://www.biorepositories.org) and belong to the collection identified as ' $z p l$ ' of Milano Bicocca institution (MIB). For molecular analysis freshly recovered worms were transferred directly into absolute ethanol and kept refrigerated at $4{ }^{\circ} \mathrm{C}$ : one paratype, and mid-section of another paratype 52 YU from Am. gutturalis (specimen vouchers MIB:zpl:01516 and MIB:zpl:01517); two fragments of one paratype $97 \mathrm{NL}$ from Bo. madagascariensis (specimen vouchers MIB:zpl:00226 and MIB:zpl:00227), two fragments of a second paratype 97 NL (specimen voucher MIB:zpl:00228 and MIB:zpl:00229) and an additional female 99 NL (specimen voucher MIB:zpl:00230); mid-section of holotype 74 NL from As. rheophilus (specimen voucher MIB:zpl:00190). DNA extracts were prepared using 5 PRIME, ArchivePure DNA Purification Kit. Rhabdias species coxI amplification and sequencing were obtained following Folmer et al. (1994) using the primer pair LCO1490 (5'-GGTCAACAAATCATAAAGATATTGG-3') and HCO2198 (5'-TAAACTTCAGGGTGACCAAAAAATCA-3'); 12S rDNA sequences were generated following Casiraghi et al. (2004) using the primer pair 12SF (5'-GTTCCAGAATAATCGGCTA-3') and 12SdegR (5'-ATTGACGGATGRTTTGTACC-3'). PCRs were performed in a volume of $20 \mu 1$ under the following final conditions: $1 \mathrm{X}$ buffer including $2.5 \mathrm{mM} \mathrm{MgCl}$ (MasterTaq kit, Eppendorf $^{\mathrm{TM}}$ ), $0.2 \mathrm{mM}$ of each dNTP, $1 \mu \mathrm{M}$ of each forward and reverse primers and $1 \mathrm{U}$ of DNA polymerase (MasterTaq kit, Eppendorf $\left.{ }^{\mathrm{TM}}\right)$. The amplicons obtained are approximately 600 and $500 \mathrm{bp}$ long, respectively. PCR products were gel-purified using the 5 PRIME, GelElute Extraction Kit and sequenced directly using ABI technology. Sequences were checked by eye with 
BioEdit sequence alignment editor (version 7.0.5; Hall 1999) using GenBank sequences as reference sequences (FM179476FM179479; FN395318-FN395323) and unambiguously aligned using ClustalX (Thompson et al. 1997). The Rhabdias species sequences are deposited in the EMBL Data Library under the following accession numbers: $R$. picardiae sp. n. $12 \mathrm{~S}$ rDNA FN434093-FN434094, coxI FN434095-FN434096; $R$. vencesi sp. n. 12S rDNA FN434097-FN434101, coxI FN434102FN434106; $R$. tanyai sp. n. 12S rDNA FN434097-FN434101, coxI FN434102-FN434106. The alignments were analysed using distance matrix method (i.e. neighbour joining). Nucleotide distances have been calculated using MEGA 4.0 (Tamura et al. 2007) - options: nucleotide, Kimura 2-parameter (K2P), complete deletion, standard error computation by bootstrapping 500 replicates.

Rhabdias biology. For life-cycle studies of $R$. vencesi, four petri dish cultures were set up as detailed in Lhermitte-Vallarino and Bain (2004), using material collected from Bo. madagascariensis (99 NL) and distilled water with active charcoal as culture medium. Cultures were kept at room temperature and checked regularly for developing stages for several days. Two cultures were made from eggs released from a female in vitro, one from larvae recovered from the lungs and one from faecal larvae extracted from the rectum of the host. Only the latter yielded developing worms.

\section{RESULTS}

Rhabdiasidae Railliet, 1916

Rhabdias picardiae sp. n. Junker, Lhermitte-Vallarino et Bain Figs. 1A-F, 3A-F, Table 1

Small worms with variable dorsal bend. Body 8.0-8.35 $\mathrm{mm}$ long, 460(530)-580(600) wide at mid-length. $\mathrm{Cu}-$ ticular vesicle with irregular folds and indentations along entire length of body, including tip of tail (Fig. 1C, D); in median view, vesicle attached laterally to inner layer of cuticle via conspicuous fibres associated with subcuticular pores (Fig. 1B); at anterior extremity more or less pronounced inflation of cuticle extending posteriorly to approximately level of oesophageal-intestinal junction; vesicle less conspicuous in mid-section and again more pronounced in tail-region. Lateral chords thick, filling body cavity in anterior region (Fig. 1B, E).

Head with six papillae in apical view (Fig. 3C, D). Four submedian papillae arranged in square, anterior to lemon-shaped oral opening (Fig. 3D); each papilla with salient sensillum and slightly protruding base. Two very small lateral papillae posterior to submedian papillae level. Amphidian canals barely visible. Cuticular velum limiting oral opening, its lumenal edge drawn out into a sharp tip in longitudinal section (Fig. 3A, B).

Lumen of buccal cavity round in transverse section (Fig. 3E), triangular at oesophageal junction. Vestibulum short, 5-7 long. Buccal capsule wall triangular in longitudinal section, 7-10 long and 23-25 wide, with granulous posterior segment where it joins oesophagus; buccal capsule ratio $0.3-0.4$; inner edge of buccal cap- sule convex, and slightly serrated in some specimens (Fig. 3A); outer edge with more or less distinct internal refringent zone; anterior apex meets velum in a pointed tip (Fig. 3A, B). Oesophagus without shoulders, its anterior edge rarely reaching mid-level of buccal capsule. Oesophagus $690-790$ long (8.6-9.9\% of TBL), slender, of equal width along anterior $2 / 3$ of its length, then gradually widening into slim bulb; width at oesophagus midlength $60-70$, bulb 95-130 wide (Fig. 1B). Body width at bulb 160(180)-300(360). Nerve ring observed in two specimens, at 235 and 250 from anterior extremity. Excretory pore not identified, obscured by cells of lateral chord (Fig. 1B). Apex of intestine wider than bulb at oesophageal-intestinal junction; intestine occupying entire width of specimen anteriorly (Fig. 1A); often filled with dark contents.

Genital tract amphidelphic; genital bend in ovaries (Fig. 1C, F); anterior genital bend at 1375-2150 from anterior extremity, posterior genital bend at 490-600 from posterior extremity. Oviducts and proximal end of ovaries folded upon themselves. In a single specimen, uterus obscuring posterior genital bend and extending posteriad past anus, ending at 265 from tip of tail. Male gametes with light-reflecting nuclei seen in anterior and/or posterior oviduct of several specimens (Fig. 1F). Vulva without salient lips, slit-like, at 4535-5050 from head (55-62\% of TBL). Uterus thin-walled, filled with numerous eggs, most of which contain first-stage larvae. Mature eggs 100-120 long and 60-69 wide $(\mathrm{n}=10)$.

Tail 270-350 long, reaching 3.5-3.8\% of TBL, tapering quickly to rounded tip. Body width at anus 120(240)225(440). Caudal vesicle voluminous with irregular indentations; terminal, elliptical to lance-shaped segment surrounding tip of tail. Tip of tail with patch of fine granular material in $5 / 7$ specimens (Fig. 1D).

Type host: Amietophrynus gutturalis (Power) (= Bufo gutturalis Power) (Bufonidae), 52 YU.

Type locality: Pretoria (25.66S, 28.15E), Gauteng Province, South Africa. Collection date: 01 September 2008.

Site of infection: Lungs.

Prevalence and intensity: $2 / 5$ hosts infected with five (52 YU) and three (53 YU) parasites, respectively.

Type materia 1: 52YU. Deposited in the MNHN collection: holotype female, one entire paratype female, two paratype females with anterior and posterior parts. One paratype female and mid-section of another used for molecular analysis; specimen vouchers MIB:zpl:01516 and MIB:zpl:01517. One paratype (N-938) in the Institute of Parasitology, BC ASCR, České Budějovice, Czech Republic. EMBL Data Library accession numbers: 12S rDNA FN434093-FN434094, coxI FN434095-FN434096.

Additional material: 53YU. Deposited in the MNHN collection.

E t y m o log y: The species is named after Dr. Jackie A. Picard, who kindly made the hosts available to us. 
Table 1. Morphometric characters of Rhabdias picardiae sp. n. from Amietophrynus gutturalis (Power) (Bufonidae) in South Africa. All measurements in micrometres unless otherwise indicated.

\begin{tabular}{|c|c|c|c|c|c|c|c|}
\hline \multirow{3}{*}{$\begin{array}{l}\text { MNHN collection } \\
\text { Specimen }\end{array}$} & \multirow{2}{*}{$\frac{\text { Holotype }}{52 \mathrm{YU}}$} & \multicolumn{6}{|c|}{ Paratypes } \\
\hline & & $52 \mathrm{YU}$ & $52 \mathrm{YU}$ & $52 \mathrm{YU}$ & $53 \mathrm{YU}$ & $53 \mathrm{YU}$ & $53 \mathrm{YU}$ \\
\hline & 2 & 1 & 3 & 4 & 1 & 2 & 3 \\
\hline Length $(\mathrm{mm})$ & 8.15 & 8.0 & - & - & 8.0 & 8.35 & - \\
\hline Width at mid-body (with vesicle) & $460(530)$ & $470(515)$ & - & - & $510(580)$ & $580(600)$ & - \\
\hline Vestibulum depth & 7 & 5 & 6 & - & 6 & 5 & 6 \\
\hline Buccal capsule length & 10 & 8 & 10 & 9 & 7 & 8 & 8 \\
\hline Buccal capsule max. external diameter & 23 & 24 & 23 & 25 & 24 & 23 & 24 \\
\hline Buccal capsule ratio & 0.4 & 0.3 & 0.4 & 0.4 & 0.3 & 0.3 & 0.3 \\
\hline Oesophagus length & 720 & 700 & 710 & 690 & 790 & 720 & - \\
\hline Oesophagus width at mid-length & 60 & 60 & 60 & 70 & 60 & 70 & - \\
\hline Bulb diameter & 105 & 95 & 100 & 95 & 120 & 130 & 115 \\
\hline Body width at bulb (with vesicle) & $170(195)$ & $160(180)$ & $280(325)$ & $265(300)$ & $205(320)$ & $300(360)$ & $240(310)$ \\
\hline Head to vulva & 5050 & 4900 & - & - & 4535 & 4575 & - \\
\hline Anterior genital bend - head & 2150 & 2000 & - & 1700 & 2075 & 1375 & - \\
\hline Posterior genital bend - tip of tail & 600 & 540 & 490 & - & 600 & $265^{\mathrm{a}}$ & - \\
\hline Tail length & 300 & 280 & 270 & 350 & 300 & 300 & - \\
\hline Width at anus (with vesicle) & $120(240)$ & $120(290)$ & $225(440)$ & $170(220)$ & $160(250)$ & $170(250)$ & - \\
\hline Apex to nerve ring & - & - & 250 & - & 235 & - & - \\
\hline Oesophagus length as $\%$ of body length & 8.8 & 8.8 & - & - & 9.9 & 8.6 & - \\
\hline Head to vulva as $\%$ of body length & 62.0 & 61.3 & - & - & 56.7 & 55.0 & - \\
\hline Tail length as \% of body length & 3.7 & 3.5 & - & - & 3.8 & 3.6 & - \\
\hline
\end{tabular}

${ }^{a}$ Uterus obscures posterior genital bend (pgb) and extends further posteriad than pgb.

Remarks. The first species to be compared with the present material are the four Rhabdias recorded from Afrotropical anurans (Table 3): $R$. africanus Kuzmin, 2001, type host Am. maculatus (Hallowell) (= Bu. maculatus), South Africa; R. bufonis (Schrank, 1788), assigned by Moravec et al. (1987) to lung worms recovered from Am. regularis (Reuss) (=Bu. regularis) in Egypt; $R$. collaris Baker, 1987, type host Le. vermiculatus (Boulanger) (Arthroleptidae) in Tanzania; and R. madagascariensis Chabaud, Brygoo et Petter, 1961, type host Ptychadena mascareniensis (Duméril et Bibron, 1841) [= Rana (Ptychadena) mascareniensis] (Ptychadenidae) in Madagascar.

Rhabdias africanus has a longer body (12.45-19.8 vs. $8-8.35)$, relatively shorter oesophagus $(3.5-4.7 \%$ vs. 8.6-9.9\%), twice longer buccal capsule (15-20 vs. 7-10) and two lateral pseudolabia (Kuzmin 2001), which we, however, consider simple swellings at the level of the amphids.

Rhabdias bufonis is in the following referred to as R. bufonis sensu Moravec, Baruš et Ryšavý, 1987, because the parasites from Am. regularis, a host with a strictly Afrotropical distribution (Frost 2009), differ from the redescriptions of Travassos (1930) and Hartwich (1972). The latter had been based on specimens recovered from European bufonids and ranids, as was the original description (not available). The main distinctive character is the size of the buccal capsule, which is of diagnostic importance (Lhermitte-Vallarino and Bain 2004, LhermitteVallarino et al. 2008); irrespective of body size, it is 15 long and 21 wide in specimens from Egypt (Moravec et al. 1987) vs. 9-12 long and 8-10 wide in European specimens (Hartwich 1972). Rhabdias bufonis sensu Moravec, Baruš et Ryšavý, 1987 has a longer buccal capsule than R. picardiae, a shorter oesophagus (510 vs. 690-790) and a longer body (13.02 $\mathrm{mm}$ vs. $8.35 \mathrm{~mm}$ ).

Rhabdias collaris has similar structures attaching the vesicle to the body, but its head is conspicuously thickened by peripheral muscle bundles, its oesophagus is shorter and shaped differently (Baker 1987b).

Rhabdias madagascariensis is shorter, $3.55 \mathrm{~mm}$ long, the oesophagus is club-shaped with a distinct dilatation anterior to nerve ring and the intestinal apex is narrower than the base of the oesophagus (Chabaud et al. 1961).

Rhabdias bdellophis Baylis, 1929 was described from the caeciliid Scolecomorphus vittatus (Boulanger) (= Bdellophis vittatus) (Gymnophiona), in Tanzania. It is distinct from $R$. picardiae in the "very vaguely defined buccal capsule", the about three times longer tail and slightly larger body (Baylis 1929) (Table 3).

Compared to the Rhabdias species from anuran hosts world-wide, $R$. picardiae is close to $R$. americanus Baker, 1978 from Anaxyrus americanus (Holbrook) (= Bu. americanus) (Bufonidae) in Canada in that the oesophagus is 770-870 long with a slightly inflated bulb, and its tail is entirely enclosed in the cuticular vesicle (Baker 1978, Kuzmin et al. 2003). However, R. americanus is distinct in having a thin tail (length/width ratio about 6 vs. $1-2.25)$, longer body $(10.7-14.1 \mathrm{~mm})$, well-developed lateral pseudolabia, a narrower buccal cavity (12-15 vs. 23-25), a much deeper vestibulum and a thicker vesicle (Baker 1978). 


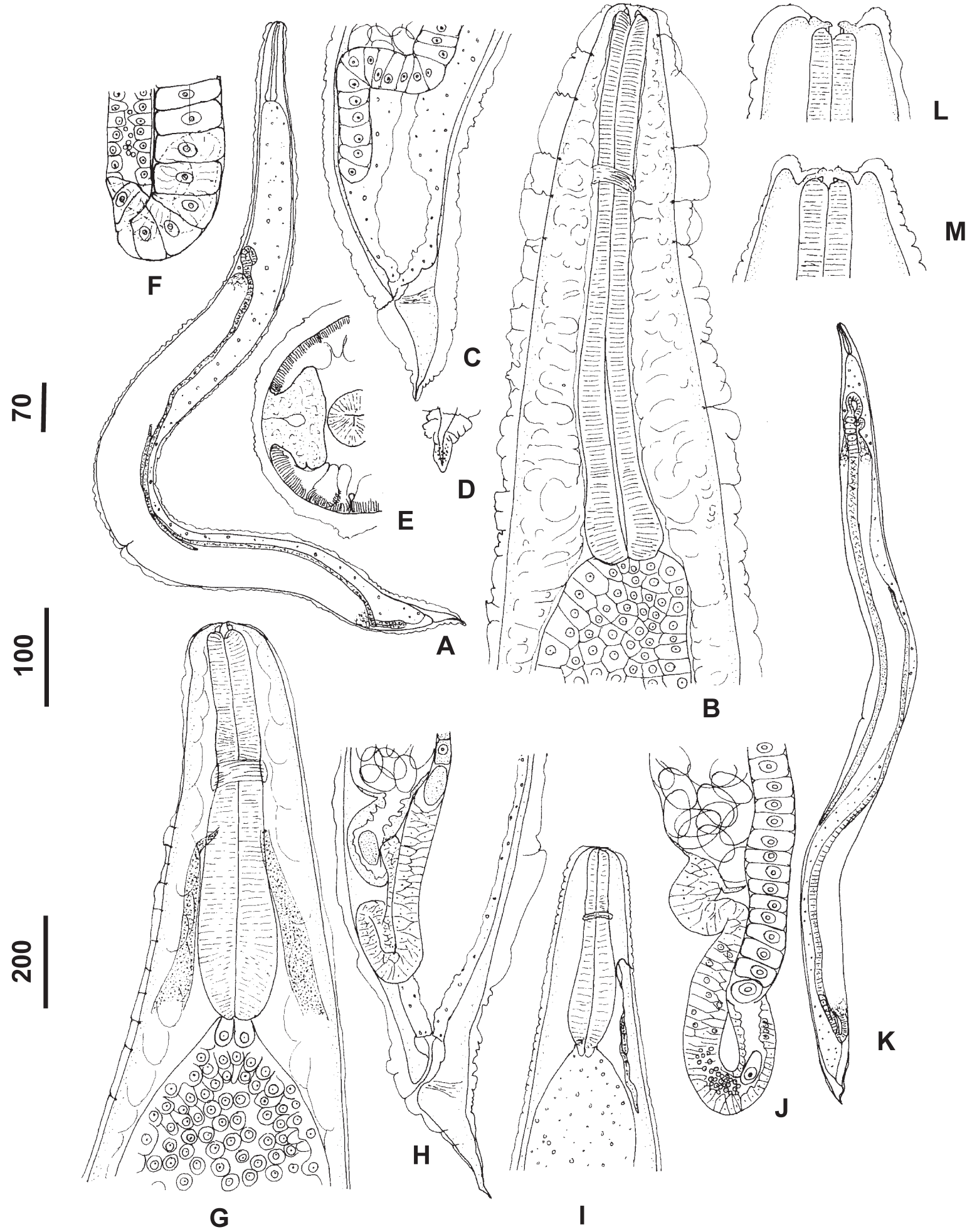

Fig. 1. A-F. Rhabdias picardiae sp. n. from Amietophrynus gutturalis in South Africa. A - habitus, left lateral view, holotype; B - anterior region, median view; $\mathbf{C}$ - posterior region, left lateral view; $\mathbf{D}$ - caudal extremity; $\mathbf{E}$ - transverse section at level of oesophagus, half body representation showing one large lateral chord; $\mathbf{F}$ - bend of terminal ovary and a part of oviduct with spermatozoa in the lumen, remainder of oviduct tightly coiled and hidden behind ovary. G-M. Rhabdias vencesi sp. n. from Boophis madagascariensis in Madagascar. $\mathbf{G}$ - anterior region, median view, with proximal part of excretory glands; $\mathbf{H}$ - posterior region, left lateral view; $\mathbf{I}$ - anterior region of another specimen, before fixation, with excretory glands and pore, lateral right view; $\mathbf{J}$ - end of posterior ovary, oviduct with ovulae and spermatozoa-like cells, and beginning of uterus; $\mathbf{K}$ - habitus, left lateral view; $\mathbf{L}, \mathbf{M}$ - head of two females, more or less invaginated. Scale bars: A, body length $8.15 \mathrm{~mm} ; \mathrm{B}, \mathrm{D}, \mathrm{G}=100 \mu \mathrm{m} ; \mathrm{C}, \mathrm{H}, \mathrm{I}, \mathrm{J}=200 \mu \mathrm{m} ; \mathrm{E}, \mathrm{F}, \mathrm{L}, \mathrm{M}=70 \mu \mathrm{m} ; \mathrm{K}$, body length $12 \mathrm{~mm}$. 
Table 2. Morphometric characters of Rhabdias vencesi sp. n. from Boophis madagascariensis (Peters) (Mantellidae) in Madagascar. All measurements in micrometres unless otherwise indicated.

\begin{tabular}{|c|c|c|c|c|c|c|c|c|c|c|c|c|}
\hline \multirow{3}{*}{$\begin{array}{l}\text { MNHN collection } \\
\text { Specimen }\end{array}$} & \multirow{2}{*}{$\frac{\text { Holotype }}{97 \mathrm{NL}}$} & \multicolumn{8}{|c|}{ Paratypes } & \multicolumn{3}{|c|}{ Additional material } \\
\hline & & $97 \mathrm{NL}$ & $97 \mathrm{NL}$ & $97 \mathrm{NL}$ & $97 \mathrm{NL}$ & $97 \mathrm{NL}$ & $97 \mathrm{NL}$ & $97 \mathrm{NL}$ & $97 \mathrm{NL}$ & 99 NL & $99 \mathrm{NL}$ & $99 \mathrm{NL}$ \\
\hline & 8 & 1 & 2 & 3 & 4 & 5 & 6 & 7 & 9 & 1 & 2 & 3 \\
\hline Length (mm) & 12.0 & 11.4 & 13.2 & 12.1 & 13.1 & 11.8 & 9.9 & 11.3 & - & 9.5 & 10.5 & 9.3 \\
\hline Width at mid-body (with vesicle) & $\begin{array}{r}600 \\
(630)\end{array}$ & 680 & 620 & 600 & 700 & $\begin{array}{r}770 \\
(810)\end{array}$ & $\begin{array}{r}680 \\
(700)\end{array}$ & 640 & - & $\begin{array}{r}570 \\
(600)\end{array}$ & $\begin{array}{r}630 \\
(650)\end{array}$ & $\begin{array}{r}560 \\
(580)\end{array}$ \\
\hline Vestibulum depth & 6 & 10 & - & 6 & - & 6 & - & 5 & - & 10 & 12 & 6 \\
\hline Buccal capsule length & 6 & 10 & - & 9 & 6 & 6 & 7 & 7 & 6 & 6 & 6 & 5 \\
\hline Buccal capsule max. external diameter & 20 & 20 & - & 22 & 20 & 19 & 20 & 21 & 20 & 22 & 22 & 19 \\
\hline Buccal capsule ratio & 0.3 & 0.5 & 0.4 & 0.3 & 0.3 & 0.3 & 0.4 & 0.3 & 0.3 & 0.3 & 0.3 & 0.3 \\
\hline Oesophagus length & 525 & 550 & 520 & 550 & 550 & 570 & 540 & 530 & 550 & 500 & 495 & 540 \\
\hline Oesophagus width at mid-length & 80 & 8 & - & 80 & 80 & 85 & 80 & 80 & 80 & 72 & 72 & 80 \\
\hline Bulb diameter & 120 & 120 & 110 & 100 & 120 & 110 & 120 & 120 & 120 & 100 & 95 & 110 \\
\hline Body width at bulb (with vesicle) & $\begin{array}{r}270 \\
(290)\end{array}$ & 230 & $\begin{array}{r}210 \\
(240)\end{array}$ & $\begin{array}{r}250 \\
(280)\end{array}$ & $\begin{array}{r}270 \\
(290)\end{array}$ & $\begin{array}{r}300 \\
(325)\end{array}$ & $\begin{array}{r}260 \\
(280)\end{array}$ & $\begin{array}{r}250 \\
(270)\end{array}$ & $\begin{array}{r}340 \\
(370)\end{array}$ & $\begin{array}{r}240 \\
(280)\end{array}$ & $\begin{array}{r}250 \\
(300)\end{array}$ & $\begin{array}{r}220 \\
(250)\end{array}$ \\
\hline Head to vulva & 6150 & 6400 & 6400 & 6490 & 6650 & 6000 & 4850 & 5500 & - & 5050 & 5350 & 4600 \\
\hline Anterior genital bend - head & 1150 & 620 & 1000 & 1130 & 940 & 1030 & 650 & 930 & 1100 & 930 & 1250 & 620 \\
\hline Posterior genital bend - tip of tail & 1130 & - & 1130 & 1070 & - & 1060 & 1080 & 900 & - & 700 & 1075 & 1100 \\
\hline Tail length & 340 & 315 & 320 & 260 & 300 & 305 & 350 & 290 & - & 230 & 375 & 240 \\
\hline Width at anus (with vesicle) & $\begin{array}{r}140 \\
(180)\end{array}$ & $\begin{array}{r}140 \\
(320)\end{array}$ & $\begin{array}{r}120 \\
(170)\end{array}$ & $\begin{array}{r}140 \\
(160)\end{array}$ & $\begin{array}{r}150 \\
(170)\end{array}$ & $\begin{array}{r}110 \\
(140)\end{array}$ & $\begin{array}{r}150 \\
(220)\end{array}$ & $\begin{array}{r}130 \\
(155)\end{array}$ & - & $\begin{array}{r}120 \\
(155)\end{array}$ & $\begin{array}{r}135 \\
(145)\end{array}$ & $\begin{array}{r}100 \\
(130)\end{array}$ \\
\hline Apex to nerve ring & 200 & 200 & - & 185 & 190 & 180 & 180 & 205 & - & 195 & 210 & 190 \\
\hline Oesophagus length as $\%$ of body length & 4.4 & 4.8 & 4.0 & 4.5 & 4.2 & 4.8 & 5.5 & 4.7 & - & 5.3 & 4.7 & 5.8 \\
\hline Head to vulva as $\%$ of body length & 51.5 & 56.0 & 48.7 & 53.7 & 50.8 & 50.8 & 49.2 & 48.7 & - & 53.2 & 51 & 49.5 \\
\hline Tail length as $\%$ of body length & 2.8 & 2.8 & 2.4 & 2.1 & 2.3 & 2.6 & 3.5 & 2.6 & - & 2.4 & 3.6 & 2.6 \\
\hline
\end{tabular}

Rhabdias vencesi $\mathrm{sp}$. $\mathrm{n}$. Junker, Lhermitte-Vallarino et Bain Figs. 1G-M, 3G-K, Table 2

Body more or less straight or slightly bent dorsally, 9.5-13.2 mm long. Width at mid-body 560(580)$770(810)$. Cuticle: vesicle more conspicuous in cephalic region, with internal transverse striae that are spaced at irregular intervals of approximately $20-30$ and $10-20$ in two specimens measured; thin or indistinct along body, but slightly more prominent in tail region.

Head with six papillae in apical view; four large, mammilate submedian and two smaller lateral papillae, each with terminal transparent cuticular apex and sensory sensillum; lateral papillae slightly posterior, submedian papillae directly adjacent to oral opening; amphids open on external surface of lateral papillae (Fig. 3H, I). Oral opening dorso-ventrally flattened, oval to spindle-shaped; velum absent. Vestibulum 5-12 long, difficult to discern in specimens with more or less invaginated head, resulting in wide range of measurements. Buccal capsule obscured by thickened apex in some invaginated specimens; no posterior segment identified; length 5-10, width 19-22, roughly triangular in longitudinal section, round in apical view; lumen cylindrical. Buccal capsule ratio 0.3-0.5. Oesophagus with shoulders, its apex extending anteriorly to mid-level or apex of buccal capsule; stout, club-shaped, 495-570 long, reaching $4.0-5.8 \%$ of TBL (Fig. 1G). Oesophagus width at mid-length $72-85$, gradually widening to maximum width of 95-120 at bulb. Body-width at bulb level 210(240)-340(370). Slight dilatation of oesophagus immediately prior to nerve ring. Nerve ring at 180-210 from head. Excretory pore observed in one specimen before fixation (Fig.1I); anterior part of excretory glands identified (Fig. 1G); at 205 from anterior extremity. Apex of intestine bell-shaped, narrow at level of oesophageal-intestinal junction, but rapidly widening posteriorly to fill almost entire width of body (Fig. 1I); anterior intestinal wall thick, with conspicuous, densely crowded, large pear-shaped cells (Fig. 1G); cells take on a more conventional shape at approximately level of anterior genital bend. Posterior part of intestine usually filled with dark brown contents.

Genital tract amphidelphic, posterior and anterior genital bend at level of muscular oviduct (Fig. 1H, J); anterior genital bend at 620-1250 from head; posterior genital bend at 700-1130 from tip of tail. Oviducts and proximal end of ovaries folded upon themselves. Numerous small, globular cells, identified as male gametes, seen in lumen of anterior oviduct of five specimens, in which this character was studied (Fig. 1J); unusual non-light reflecting nuclei of spermatozoa suggest they are degenerating; same cells present in posterior oviduct of one of these specimens, but posterior oviduct of remaining four specimens obscured by intestinal contents. Vulva slit-like, inconspicuous, without salient lips, situated in mid-region of body at 4600-6650 from head or $48.7-56 \%$ of TBL. Apex of ovaries far overlapping level of vulva. Uterus sac-like, thin-walled, filled with numerous eggs, the majority of which contain first-stage larvae. Mature eggs 110-148 long and 56-72 wide $(\mathrm{n}=10)$.

Tail conical, tapering gradually to slightly rounded tip. Tail length $230-375$ or $2.1-3.6 \%$ of TBL. Caudal vesi- 
cle with conspicuous inflation at anus, body width at that level 100(130)-150(220). Tip of tail without vesicle.

Type host: Boophis madagascariensis (Peters) (Mantellidae). Type locality: Import from Madagascar; exact locality unknown. Collection date: 28 February 2008.

Site of infection: Lungs.

Prevalence and intensity: Type host specimen (97NL) harbouring 11 females, and a second host (99NL) harbouring 4 females.

Type material: 97NL. Deposited in the MNHN collection: female holotype, eight paratype females. Two fragments of two paratypes each used for molecular analysis; specimen vouchers MIB:zpl:00226, MIB:zpl:00227, MIB:zp1:00228 and MIB:zpl:00229 respectively. One paratype (N-939) in the Institute of Parasitology, BC ASCR, České Budějovice, Czech Republic. EMBL Data Library accession numbers: 12S rDNA FN434097-FN434101, coxI FN434102-FN434106.

Additional material: 99NL. Deposited in the MNHN collection: three females. One female used for molecular analysis (specimen voucher MIB:zpl:00230).

Etymology: The new species is named after Dr. Miguel Vences in recognition of his significant contribution to our knowledge of the amphibian fauna of Madagascar.

Remarks. Rhabdias vencesi most closely resembles $R$. madagascariensis. In both species the oesophagus is club-shaped with an anterior dilatation prior to the nerve ring, and the apex of the intestine is narrow. However, $R$. madagascariensis is readily distinguished by its smaller body and the proportionally longer oesophagus (3.55 vs. $9.3-13.2 \mathrm{~mm}$, and 7.6 vs. $4.0-5.8 \%$ of TBL) and the anterior part of the intestine, which remains slender (Chabaud et al. 1961), whereas that of $R$. vencesi expands rapidly. Its mouth is round as opposed to dorso-ventrally flattened as in $R$. vencesi.

The remaining Afrotropical species are equally distinct (Table 3). Rhabdias africanus differs in having two distinct swellings at the level of the amphids, papillae that overhang the oral opening giving the mouth an octagonal shape, a longer buccal capsule (15-20 vs. 5-10) and a slender oesophageal bulb (65-80 vs. 95-120) (Kuzmin 2001). While being of similar length (9-12 vs. 5-10), the buccal capsule ratio of $R$. bufonis sensu Moravec, Baruš et Ryšavý, 1987 is greater than that of $R$. vencesi $(0.7$ vs. 0.3-0.5) and the intestinal apex is broader than the oesophageal base (Moravec et al. 1987). Rhabdias collaris has a conspicuous cephalic swelling, a round mouth and a distinctly longer vestibulum (42 vs. 5-12) (Baker 1987b). Rhabdias picardiae is shorter, has a lemonshaped mouth opening, small lateral papillae and a buccal capsule with a distinct posterior segment. Furthermore, its oesophagus is long and narrow (8.6-9.9 vs. $4.0-5.8 \%$ of TBL) and the intestinal apex is wider than the oesophagus at the oesophageal-intestinal junction. Rhabdias bdellophis is distinct in having a shorter body and tail, a weakly developed buccal capsule and a relatively longer oesophagus (7.8-8.0 vs. $4.0-5.8 \%$ of TBL).

When compared to Rhabdias species from anuran hosts world-wide, an arrangement of head papillae with welldeveloped, salient lateral papillae as seen in $R$. vencesi is also present in $R$. joaquinensis Ingles, 1935 from a ranid in California, Rana aurora Baird et Girard (Kuzmin et al. 2003). This species is distinct, however, in having an attenuated anterior body half, a postequatorial vulva and a cylindrical oesophagus (Kuzmin et al. 2003).

Rhabdias ohlerae sp. n. Junker, Lhermitte-Vallarino et Bain Figs. 2A-F, 3L, Q, Table 3

Body small, $6.5 \mathrm{~mm}$ long, dorsally bent, tapering at both ends; width at mid-body 380(420). Thin vesicle present along entire length of body, including tip of tail; difficult to discern in some places. Anterior extremity tapering rapidly from level of anterior genital bend anteriad, terminating in distinct dilatation that is set off from body by slight constriction (Fig. 2D, C); cephalic dilatation 90 long, 70 wide. Mouth opening limited by cuticular velum. Vestibulum 5 deep. Buccal capsule 11 long and 16 wide; ratio 0.7; posterior segment forming distinct ridges, where it rests upon oesophagus (Fig. 3L); lumen of buccal capsule funnel-shaped. Oesophagus club-shaped, 450 long $(6.9 \%$ of TBL), with shoulders. Apex of oesophagus not reaching anterior border of buccal capsule (Fig. 3L). Anterior dilatation of oesophagus present at 100 from head, 41 wide, anterior to nerve ring (Fig. 2D). Subsequently, gradual increase in oesophagus width from 35 at mid-length to maximum of 55 at indistinct posterior bulb. Nerve ring and excretory pore at 150 and 190 from apex, respectively. Apex of intestine with a shallow depression to accommodate base of oesophagus, which is narrower than intestinal apex at junction (Fig. 2D). Intestine thickwalled, its cells forming a distinct giraffe pattern with narrow interstitial spaces (Fig. 2D); taking up entire width of body anteriorly, but narrowing at approximately level of anterior genital bend; filled with dark brown contents posteriorly.

Genital tract amphidelphic. Anterior genital bend in ovary, 850 from head; posterior genital bend in oviduct (Fig. 2F), 675 from tip of tail. Oviducts and proximal end of ovaries folded upon themselves. Ovary apices just overlapping vulva. Narrow band (30-50 wide) of small, poorly defined and irregularly arranged cells in posterior ovary interpreted as testis zone (Fig. 2E). Vulva without salient lips, at 3120 from head (48\% of TBL). Uterus thin-walled, sac-like, filled with numerous eggs, many of which contain first-stage larvae. Mature eggs 104-120 long by $58-65$ wide $(\mathrm{n}=10)$.

Tail conical, 275 long, reaching $4.2 \%$ of TBL. Width at anus 140 (190). Distinct postanal swelling of body in lateral view (Fig. 2B). Caudal vesicle slightly more con- 


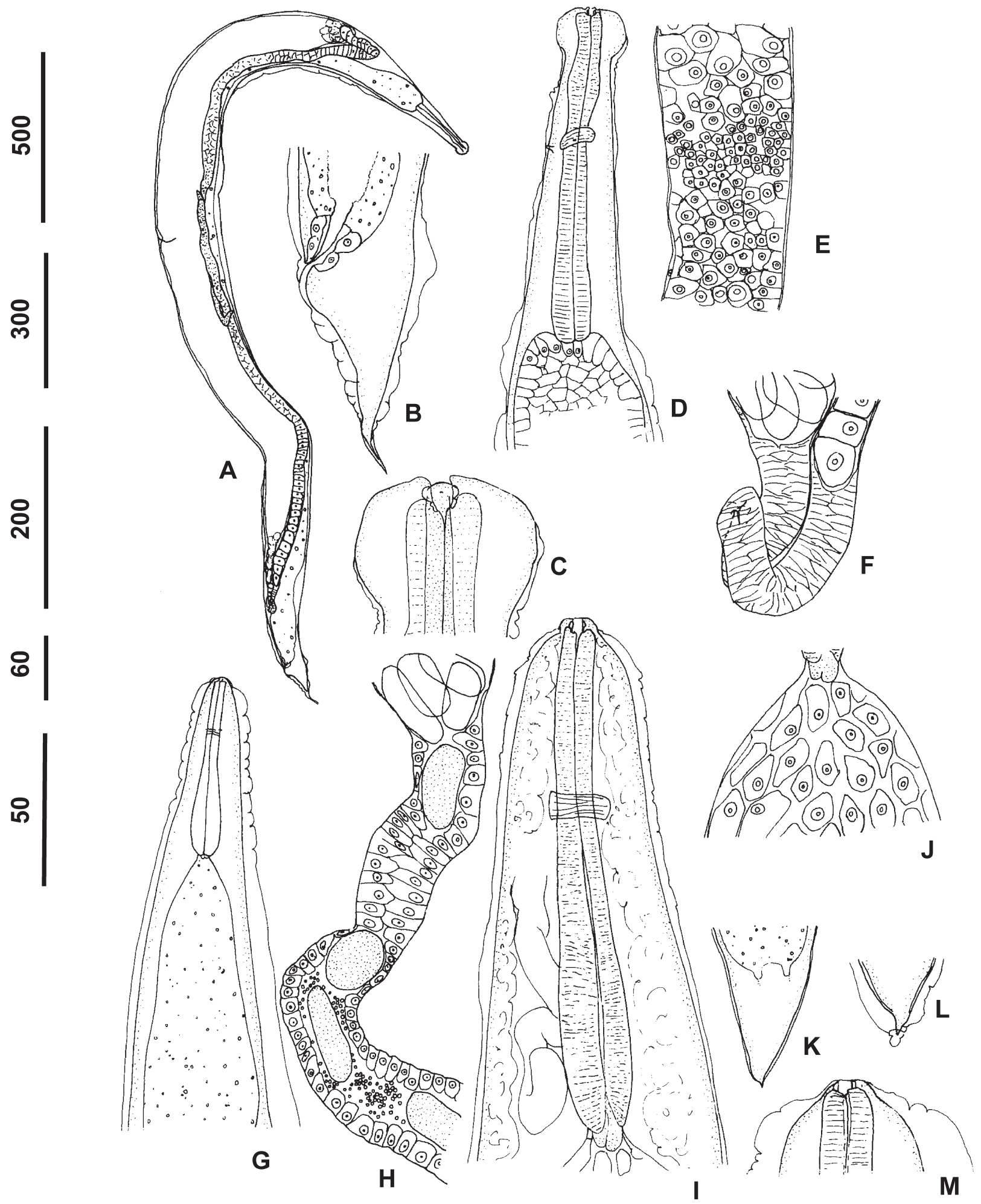

Fig. 2. A-F. Rhabdias ohlerae sp. n. from Leptopelis brevirostris in Cameroon. A - habitus, left lateral view; B - posterior region, left lateral view; $\mathbf{C}$ - head, lateral view; D - anterior region, left lateral view; $\mathbf{E}$ - proximal part of male area in ovary (top of drawing indicates direction of ovary apex); $\mathbf{F}$ - end of posterior ovary, oviduct and beginning of uterus. G-M. Rhabdias tanyai sp. $\mathrm{n}$. from Astylosternus rheophilus in Cameroon. $\mathbf{G}$ - anterior region, before fixation; $\mathbf{H}$ - oviduct with ovulae and, possibly degenerate, spermatozoa up to beginning of uterus; I - oesophageal region with one of the excretory cells, dorso-ventral view; $\mathbf{J}$ - apex of intestine; $\mathbf{K}$ - posterior region with end of intestine and rectum, ventro-dorsal view (anus not identified); $\mathbf{L}-$ caudal extremity, ventrodorsal view; $\mathbf{M}$ - anterior extremity, before fixation. Scale bars: A, body length $6.5 \mathrm{~mm} ; \mathrm{B}, \mathrm{D}, \mathrm{F}, \mathrm{H}, \mathrm{I}, \mathrm{J}=200 \mu \mathrm{m} ; \mathrm{C}, \mathrm{E}, \mathrm{L}=50 \mu \mathrm{m}$; $\mathrm{G}=500 \mu \mathrm{m} ; \mathrm{K}=300 \mu \mathrm{m} ; \mathrm{M}=60 \mu \mathrm{m}$. 
spicuous than along body, with irregular folds. Tip of tail 50 long, demarcated from rest of tail by sharp bend, enclosed in thin vesicle.

Type host: Leptopelis brevirostris (Werner) (Arthroleptidae).

Type locality: Petit Mont, Etinde Summit, Mount Cameroon, Cameroon $(4.06 \mathrm{~N}, 9.12 \mathrm{E})$. Collection date: 28 April 2007.

Site of infection: Lungs.

Prevalence and intensity: A single specimen from a single host.

Type materia 1: Holotype female: 26NL. Deposited in the MNHN collection.

Etymology: The species is named after Prof. Anne-Marie Ohler, for her contribution to the taxonomy of Asiatic amphibians and her assistance with the identification of some of the hosts examined herein.

Remarks. The distinct cephalic dilatation readily distinguishes $R$. ohlerae from its congeners in the Afrotropical region, excepting $R$. collaris, as well as from the majority of Rhabdias species from anuran hosts worldwide. While in $R$. collaris the cephalic inflation consists of two lobe-like, divergent structures, which open a wide, funnel-shaped vestibulum of considerable depth between them (42, measured on drawing) (Baker 1987b), that of $R$. ohlerae is round, with a small oral opening that leads into a short vestibulum (5 deep).

From anurans world-wide, the two other species with cephalic dilatations that are not based on vesicular inflation only are $R$. androgyna Kloss, 1971 from a Brazilian host identified as Bu. typhonius (L.) by Kloss (1971), but most likely Rh. margaritifera (Laurenti) (Frost 2009), and $R$. sphaerocephala Goodey, 1924 from the toad Bu. bufo (Linnaeus) (= Bu. vulgaris) in England, with additional details on head morphology given by Kuzmin et al. (2007). Rhabdias androgyna, as illustrated by Kloss (1971), is distinguished from the new species by a thicker body vesicle, deep vestibulum and longer body as well as oesophagus (9-13 mm and 577-618, respectively).

Rhabdias ohlerae most closely resembles $R$. sphaerocephala, being similar in body length $(6.5 \mathrm{~mm}$ vs. 6-6.5 mm) and oesophagus length (450 or $6.9 \%$ of TBL vs. $430-450$ or $6.6-7.5 \%$ of TBL) (Goodey 1924a; calculations based on minimum and maximum values). Further similarities are the shape of the oesophagus, including the anterior swelling situated just posterior to the cephalic dilatation, and the apex of the intestine, which encompasses the base of the oesophagus. However, the cephalic dilatation of $R$. sphaerocephala is distinctly wider than that of $R$. ohlerae (115-120 vs. 70; both sets of measurements excluding vesicle), the vesicle is thicker and the tail is shorter in $R$. sphaerocephala (190-220 or 2.9-3.4\% of TBL vs. 275 or $4.2 \%$ of TBL) (Goodey 1924a; calculations based on minimum and maximum values).
Rhabdias tanyai sp. n. Junker, Lhermitte-Vallarino et Bain Figs. 2G-M, 3M, Table 3

Body with slight dorsal bend (Table 3), length $>13.9 \mathrm{~mm}$ (length of anterior plus posterior fragment). Thin vesicle present along entire length of body, including tip of tail. Buccal capsule and oesophageal apex forming a flattopped projection at cephalic end in fixed specimen; the same projection observed prior to fixation, but less pronounced (Figs. 2 G, I, M, 3M). Buccal capsule 12 long and 23 wide, with a ratio of 0.5 ; posterior segment not resting on but rather inserted into the oesophageal apices (Fig. 3M); anterior and posterior segments form shoe soleshape; lumen of buccal capsule cylindrical. Oesophagus club-shaped, with shoulders, but apex not reaching midlevel of buccal capsule; 650 long, reaching a maximum of $4.7 \%$ of TBL when taking TBL as the sum of the anterior and posterior fragment; oesophagus width at midlength 60, gradually increasing to maximum of 95 at bulb. Body width at bulb 270 (290). Nerve ring at 235 from apex, excretory pore not observed, but a long excretory gland identified. Apex of intestine bell-shaped, narrow at oesophageal-intestinal junction, but rapidly widening to take up almost entire width of body (Fig. 2G). Intestine thick walled, its cells arranged in a giraffe pattern with wide interstitial spaces (Fig. 2J); filled with dark brown contents posteriorly; terminating in two short, peg-like extensions.

Genital tract amphidelphic. Removal of mid-section made measurements impossible. Vulva absent from both fragments. It is difficult to assess if the following observations are typical features or result from specimen manipulation. Anterior oviduct-uterus junction observed, with uterus extending considerable distance anteriad from junction. Anterior genital bend not seen, but uterus clearly anterior-most portion of anterior genital tract. Ovaries disposed in generous loops across width of body, containing ovulae arranged in transverse bands of 5-6 each. Testis zone identified in posterior ovary. Lumen of anterior oviduct containing similar but smaller cells representing spermatozoa, possibly degenerate (Fig. 2H). Uterus thin-walled, sac-like, filled with numerous eggs, many of which contain first-stage larvae. Mature eggs 96-105 long by $50-62$ wide $(\mathrm{n}=5)$.

Tail conical, with short, stubby tip, 275 long, reaching a maximum of $2.0 \%$ of TBL, when taking TBL as the sum of the anterior and posterior fragments. Tip of tail enclosed in vesicle.

Type host: Astylosternus rheophilus Amiet (Arthroleptidae).

Type locality: Forest below Oku village (6.22N, 10.52E), Mount Oku, Cameroon. Collection date: 10 May 2007.

Site of infection: Lungs.

Prevalence and intensity: A single female from a single host. 

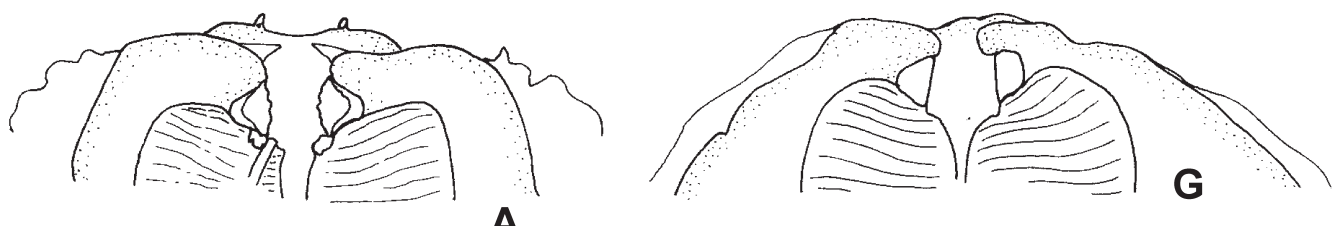

A
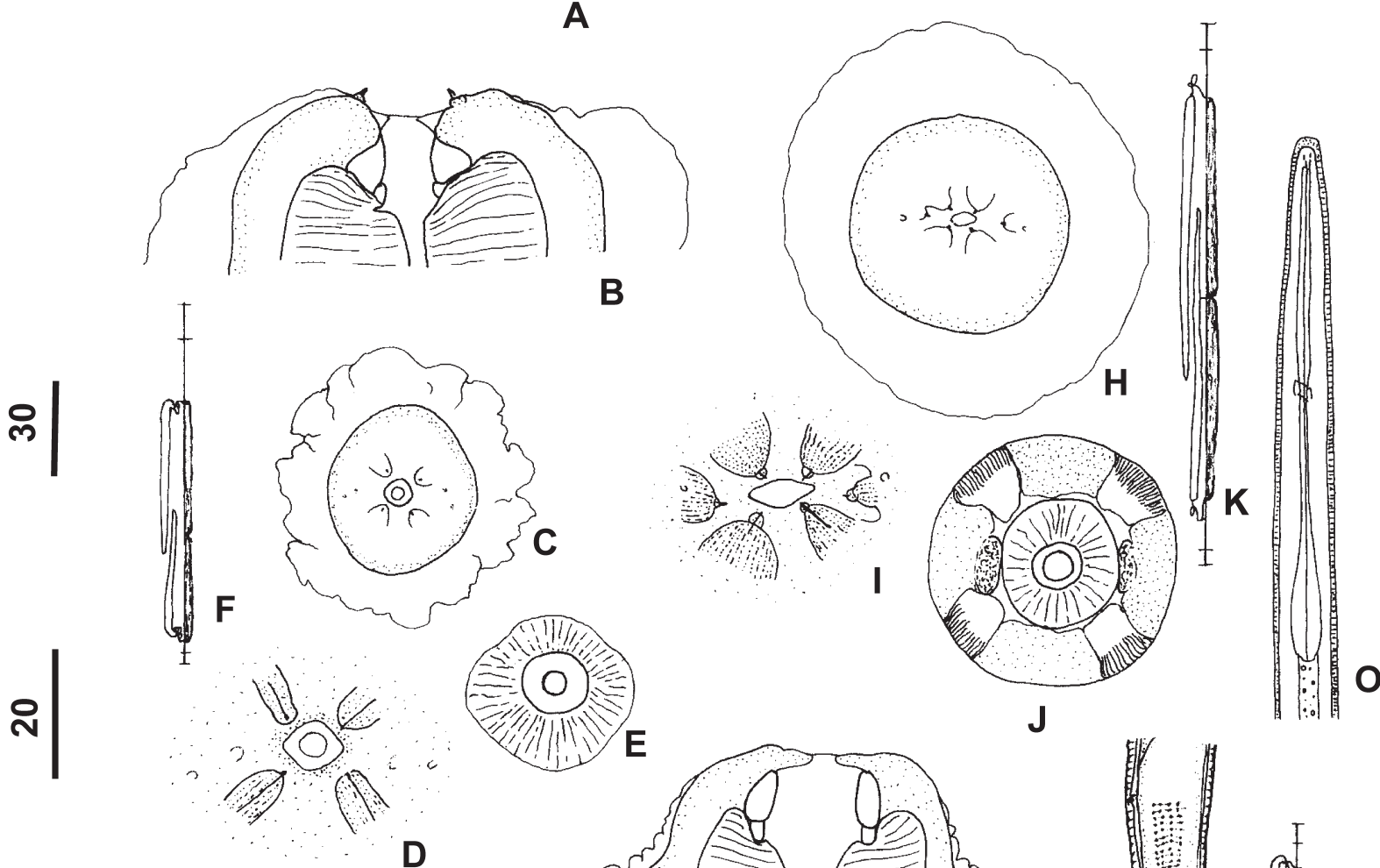

B

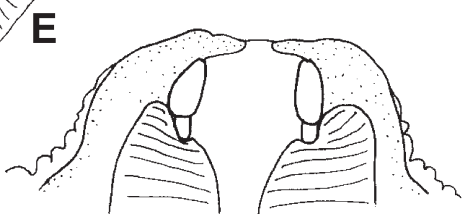

M
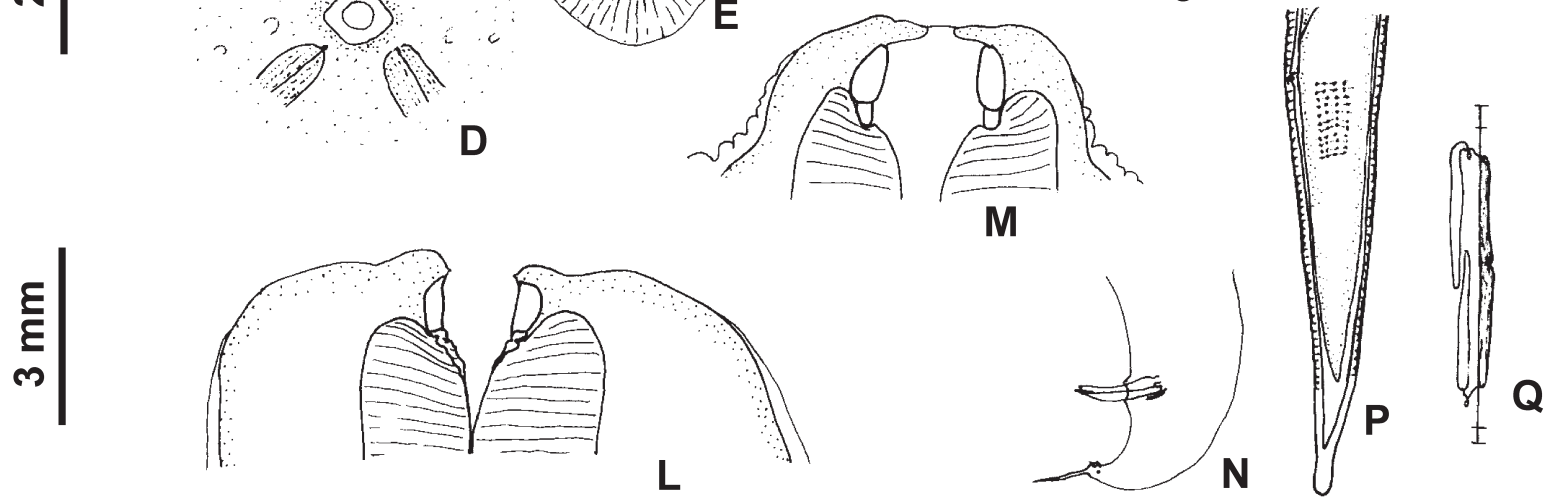

Fig. 3. A-F. Rhabdias picardiae sp. $n$. A - head, dorso-ventral view; B - head, lateral view (another specimen); C-E - frontal view; $\mathbf{C}$ - head; D - sensory papillae and mouth; $\mathbf{E}$ - buccal capsule and apex of oesophagus, transverse optical section; $\mathbf{F}$ - diagrammatic representation of holotype. G-K. Rhabdias vencesi sp. n. G - head, subdorso-ventral view; H, I - frontal view; H - head; I - sensory papillae and mouth; $\mathbf{J}$ - buccal capsule, apex of oesophagus, and the particular lateral structures along the oesophagus, transverse optical section; K - diagrammatic representation of holotype. L. Rhabdias ohlerae sp. n., buccal cavity and capsule, lateral view. M. Rhabdias tanyai sp. n., buccal cavity and capsule, dorso-ventral view. N-P. Free-living stages of $R$. vencesi $\mathrm{sp}$. $\mathrm{n}$. $\mathbf{N}-$ male, posterior region, left lateral view; $\mathbf{O}, \mathbf{P}$ - infective larva, anterior and posterior region, right and left lateral view, respectively. Q. Rhabdias ohlerae sp. n., diagrammatic representation of holotype. Scale bars: A, B, D, E, G, I, L, M, P = $20 \mu \mathrm{m} ; \mathrm{C}, \mathrm{H}, \mathrm{J}, \mathrm{N}, \mathrm{O}=30 \mu \mathrm{m} ; \mathrm{F}, \mathrm{K}, \mathrm{Q}=3 \mathrm{~mm}$.

Type material: 74NL; a single worm recovered. Deposited in the MNHN collection: posterior and anterior part of female holotype. Mid-section removed for molecular analysis; specimen voucher MIB:zpl:00190. EMBL Data Library accession numbers: 12S rDNA FN434097-FN434101, coxI FN434102-FN434106.

Etymology: The new species is named after Dr. Vincent Tanya, our colleague in Cameroon (EU projects on onchocerciasis), and in recognition of his administrative help concerning the field trip.
Remarks. Rhabdias tanyai can be distinguished from species hitherto described from Malagasy and African hosts (Table 3 ) by the cephalic projection, the shoe soleshape of its buccal capsule and the way the posterior segment of the capsule is inserted into the oesophagus.

The only other Rhabdias species from anuran hosts with an anterior cephalic projection similar to that seen in $R$. tanyai is $R$. brachylaimus (von Linstow, 1903), originally described by von Linstow (1903) as Angiostomum brachylaimus from Du. melanostictus (Schneider) (=Bu. 


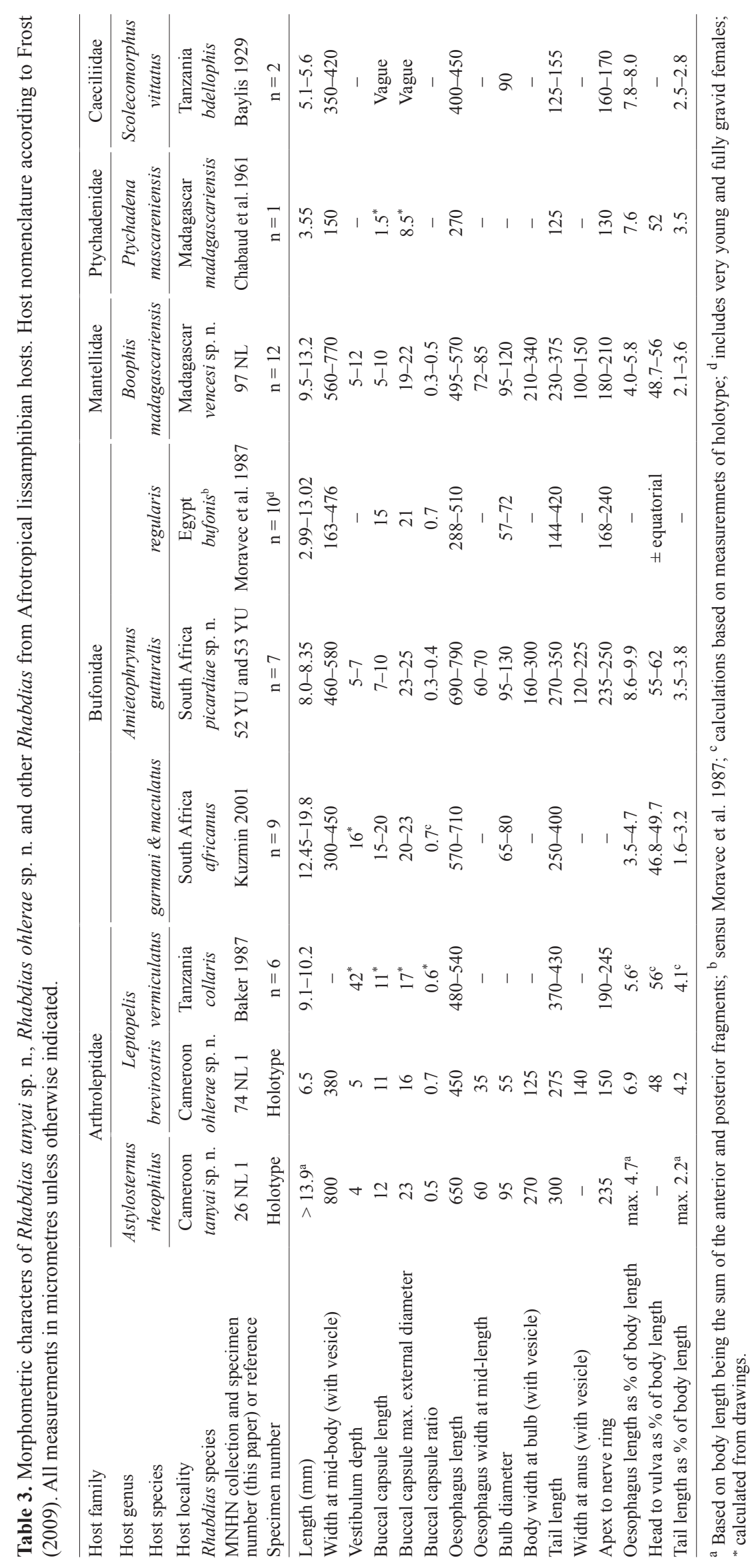


melanostictus) in Thailand and subsequently by Yuen (1965) from lissamphibians in Malaysia. Based on von Linstow's (1903) description, $R$. brachylaimus is, however, considerably shorter than $R$. tanyai $(8.8 \mathrm{~mm}$ vs. $>13.9 \mathrm{~mm}$ ) and its oesophagus and tail are longer, reaching $6.7 \%$ and $4 \%$ of TBL, respectively. While specimens of $R$. brachylaimus described by Yuen (1965) are comparable to $R$. tanyai in body length, their oesophagus ranges from 270 to 370 in length only, compared to 650 .

\section{Molecular analyses}

Taking an integrated taxonomical approach based on both morphological characterisation and classical DNA barcoding (Ferri et al. 2009), DNA sequences of three of the four species described herein were analysed. Comparison of the $12 \mathrm{~S}$ rDNA and coxI sequences of $R$. picardiae, $R$. tanyai and $R$. vencesi confirmed their validity.

Data obtained, based on K2P distance matrix, showed a low nucleotide intraspecific distance both for $R$. vencesi. (12S rDNA $0.2 \%$ and coxI $0.2 \%$ ) and $R$. picardiae (12S rDNA $0.3 \%$ and the sequences were identical in coxI), for which more than a single specimen could be analysed. Moreover, our results confirmed placement of the three species in three distinct Molecular Taxonomic Units (MOTU). In fact, the nucleotide interspecific distances (K2P) for the two molecular markers 12S rDNA and coxI, respectively, are: $6.7 \%$ (standard error $1.4 \%$ ) and $9.9 \%$ (standard error 1.7\%) between R. picardiae and R. vencesi; $5.8 \%$ (standard error $1.4 \%$ ) and $13.2 \%$ (standard error $1.2 \%$ ) between $R$. picardiae and $R$. tanyai; and 7.9\% (standard error $1.6 \%$ ) and $16.2 \%$ (standard error $1.7 \%$ ) between $R$. vencesi and $R$. tanyai.

\section{Free-living stages of Rhabdias vencesi}

Descriptions of free-living stages of $R$. vencesi are based on material obtained from cultured larvae collected from the rectum of host 99 NL. Male and female adults were observed after 3 days, and several motile infective larvae were detected 7 days after the culture was started. Soon a high mortality rate was observed due to bacterial colonies.

Female: not measured, not drawn. Male $(n=1)$ (Fig. 3N): body length 578, with short lateral alae; tail 53 long, including a tail filament of 9 length; spicules 26 and 28, gubernaculum 13 long. Caudal papillae not studied in detail, but two subterminal pairs conspicuous.

Infective third-stage larva $(\mathrm{n}=1)$ (Fig. 3O, P): enclosed in exuvial sheath, with checkered ornamentation; posterior part of sheath regularly attenuated, without subterminal indentation and bosses; tip of sheath blunt. Tail of larva tapering to conical, sharply pointed tip. Measurements exclude sheath: 575 long, 20 wide; nerve ring at 80 from head; buccal cavity funnel-shaped; buccal capsule 11 deep, 7 wide, composed of two segments; oesophagus 175 long; tail 58 long; genital anlage 50 long, situated at mid-length of intestine.

\section{DISCUSSION}

The Rhabdias fauna of Afrotropical anurans appears diverse and to date, including the present paper, eight species have been reported from four families of anuran hosts (Table 3). Neither these lungworms nor their hosts have been recorded from any of the other zoogeographic regions.

In the new species, the shape and structure of the buccal capsule is diverse; it can comprise a single segment as in $R$. vencesi, or two more or less distinct ones as in the remaining three species; its wall can be simple, or double as in $R$. picardiae. The mouth is subsphaerical or dorsoventrally flattened ( $R$. picardiae and $R$. vencesi, respectively), and the lateral head papillae may be developed or reduced. These characters cannot be compared with many other species, but buccal capsule size, shape and size of the oesopahgus, body size and the configuration of the apex of intestine, to name a few, can be used for species differentiation (Kuzmin et al. 2003, Tkach et al. 2006). The latter are equally useful when distinguishing parasites from chamaeleonids (Lhermitte-Vallarino and Bain 2004, Lhermitte-Vallarino et al. 2008, 2009a, b).

At present, the Rhabdias fauna of Afrotropical anurans presents the following picture. Three species, $R$. bufonis sensu Moravec, Baruš et Ryšavý, 1987, R. africanus, and $R$. picardiae, parasitise hosts of the family Bufonidae, represented by a single genus, Amietophrynus (formerly included in Bufo), which is limited to sub-Saharan Africa (Frost 2009). All four host species occur in savanna habitat and their distribution overlaps to varying degrees, with Am. gutturalis having the widest and Am. maculatus the narrowest geographic range (Passmore and Carruthers 1979). Several comments can be made when considering the Rhabdias species and host families in the Afrotropics.

In bufonids, while $R$. picardiae and $R$. bufonis sensu Moravec, Baruš et Ryšavý, 1987 are distinctly different (Table 3 ), their hosts are morphologically very close. Molecular evidence, however, suggests that the two bufonids separated some 5 to 6 million years ago (Channing and Howell 2006). The two South African species, $R$. picardiae and $R$. africanus, are morphologically no closer to each other than they are to $R$. bufonis sensu Moravec, Baruš et Ryšavý, 1987. In fact, with respect to relative oesophagus length, $R$. africanus and $R$. picardiae occupy opposite extremes of the wide range seen in this character in anuran hosts. The host of $R$. picardiae was collected in the Central Bushveld bioregion, whereas the two hosts of $R$. africanus were collected in the South African Lowveld Bushveld in the Kruger National Park (Mucina and Rutherford 2006). However, the three species from African bufonids share a common trait regarding oesophagus morphology: the bulb is not very distinct, and the anterior dilatation, which is relatively common in Rhabdias from other bufonids (Goodey 1924a, Yuen 1965, Kloss 1971, Tkach et al. 2006, Martínez-Salazar and León-Règagnon 
2007), is absent. In addition, none of the species from African bufonids have well-developed pseudolabia. Contrary to this, pseudolabia are present in several Rhabdias from bufonids in the Nearctic (Baker 1978), Neotropic (Kuzmin et al. 2007, Martínez-Salazar and León-Règagnon 2007) and Oriental region ( $\mathrm{Lu} \mathrm{1934).}$

A further three species occur in Arthroleptidae (Table 3), with $R$. collaris and $R$. ohlerae parasitising Leptopelis, and $R$. tanyai using Astylosternus. Both genera are restricted to sub-Saharan Africa. In Cameroon, $R$. ohlerae and $R$. tanyai are morphologically very dissimilar (Fig. 2). This is not surprising considering that their respective hosts, Le. brevirostris and As. rheophilus, were collected on two isolated mountains of the Cameroonese volcanic chain, where endemicity is high in plants as well as animals (Letouzey 1985, Amiet 1987, Vivien 1991, Maley 1996, Küper et al. 2004). Interestingly, both $R$. collaris and $R$. ohlerae, collected from allopatric forest species of the genus Leptopelis, have cephalic dilatations and are close in other aspects of their morphology as well. Since $R$. androgyna (Kloss 1971) and $R$. sphaerocephala (Goodey 1924a) from Bufonidae in Brazil and Europe, respectively, possess similar dilatations without sharing any further resemblances, it is difficult to judge whether cephalic inflations indicate a common ancestry or are the result of convergent development preventing expulsion from the host's lungs (Baker 1987b).

A single species, $R$. vencesi, was recovered from Mantellidae (Boophis), a family restricted to Madagascar and Mayotte (Frost 2009). In the same region, R. madagascariensis was described from Ptychadena. The family Ptychadenidae was historically restricted to sub-Saharan Africa, but the genus Ptychadena has subsequently been introduced on Madagascar, the Seychelles and the Mascarene Islands. Both Malagasy Rhabdias species are closely related, suggesting speciation through hostswitching, a process that occurred in many groups of nematode parasites (Durette-Desset et al. 1985, Guerrero et al. 2002).

All Rhabdias species from anuran hosts described herein differ from the large species of Rhabdias in African and Malagasy chameleons in the size of the buccal capsule. In R. chamaeleonis (Skrjabin, 1916), R. jarki LhermitteVallarino et Bain, 2004, R. cristati Lhermitte-Vallarino et Bain, 2008, R. okuensis Lhermitte-Vallarino et Bain, 2008, $R$. brevicorne Lhermitte-Vallarino, Junker et Bain, 2009, $R$. mariauxi Lhermitte-Vallarino et Bain, 2009, R. nasutum Lhermitte-Vallarino, Junker et Bain, 2009, R. rabetafikae Lhermitte-Vallarino, Junker et Bain, 2009 and R. rhampholeonis Lhermitte-Vallarino et Bain, 2009 the buccal capsule is distinctly wider $(\geq 35)$ than that seen in Rhabdias from anurans in the Afrotropical region (Table 3). Contrary to this, the buccal capsule of the two small species from chameleons, R. gemellipara Chabaud, Brygoo et Petter, 1961 and Rhabdias sp. of Lhermitte-Vallarino et al. (2009), is narrower $(\leq 17)$ than that of the new taxa described herein (Lhermitte-Vallarino and Bain 2004, Lhermitte-Vallarino et al. 2008, 2009a, b), excepting $R$. ohlerae, which is easily distinguished by its dilated anterior end.

The four Rhabdias species described herein share a number of biological characters with their congeners from other lissamphibian and saurian hosts, such as hermaphrodism in the parasitic females. Male gametes were positively identified in the oviducts of $R$. picardiae and testis zone in the posterior ovary of $R$. tanyai, while cells interpreted as such were seen in the oviduct of $R$. vencesi and in the posterior ovary of $R$. ohlerae. Contrary to Baker (1979), however, who observed protandry in R. america$n u s$ and $R$. ranae, this was not seen in the present material. Rather spermatozoa seem to be produced intermittently during the females' entire life, as in some Rhabdias from other lissamphibian (Travassos 1926, Chu 1936) and chameleon hosts (Lhermitte-Vallarino and Bain 2004, Lhermitte-Vallarino et al. 2008, 2009a, b). Oviduct structure was uniform in the four new species, consisting of high, narrow cells as in Rhabdias species from Chamaeleonidae. No seminal receptacle as described by Baker (1979) in oviducts of young adults of $R$. americanus was identified.

Additional biological traits shared by $R$. vencesi, for which part of the life history could be studied, and Rhabdias from other lissamphibians and saurians, include heterogonic free-living males and females. Compared to species from chamaeleonids, the male caudal filament is almost twice as long (Lhermitte-Vallarino and Bain 2004, Lhermitte-Vallarino et al. 2008, 2009a).

Two morphological characters of the infective stage are of interest: the ornamentation of the sheath and the shape of the tail extremity of the larva. Rhabdias vencesi shares the checkered sheath of its infective larva with congeners from chamaeleonids (Lhermitte-Vallarino et al. 2004, 2005, 2008, 2009a), R. fuscovenosa from a snake (Goodey 1924b) and infective larvae of other Rhabdiasidae, such as Entomelas entomelas (Dujardin, 1845) (Seurat 1920), Pneumonema tiliquae Johnston, 1916 (Ballantyne 1991) and Chabirenia cayennensis Lhermitte-Vallarino, Bain, Bertani, Voza, Attout et Gaucher, 2005 (LhermitteVallarino et al. 2005). The ornamentation of the sheath is easily missed. Its description in several genera and species of Rhabdiasidae suggests that it is a character of Rhabdiasidae.

The tail extremity of the infective larva of $R$. vencesi, the first lung worm from Mantellidae, is pointed. In four of five species from bufonid and ranid anurans, for which this character is sufficiently described or illustrated, the tail extremity is blunt (Yuen 1965, Baker 1979), but pointed in the remaining one (Travassos 1926). It is also blunt in species from ophidians (Kuzmin 1999, Kuzmin and Miskov 1999). The bifid tail reported by Chu (1936) is the result of confusion with infective larvae of Strongyloides 
Grassi, 1879. The four recently studied Rhabdias species from chamaeleonids present a particular morphology in that the tail is blunt and carries a small number of buds (Lhermitte-Vallarino et al. 2004, 2005, 2008, 2009a).

Acknowledgements. This work was supported by the Agence Nationale de la Recherche Biodoversity Project, Iles Forestières Africaines, IFORA, 2006-2009, and by the Partenariat Hubert
Curien, Programme Galileo. We thank Ivo Melle Ngwese, our field guide, and Laure Pierre who is in charge of the MNHN reptile collection. We also thank the Cameroon Ministry of Forests and Fauna and Ministry of Scientific Research and Innovation for their ongoing support of research efforts in Cameroon. The visit of K. Junker to the Muséum National d'Histoire Naturelle, Paris was financed by the National Research Foundation, South Africa (KISC grant No. 67445).

\section{REFERENCES}

Amiet J.-L. 1987: Aires disjointes et taxons vicariants chez les anoures du Cameroun: implications paleoclimatiques. Alytes 6: 99-115.

Anderson R.C. 1992: Nematode Parasites of Vertebrates, their Development and Transmission. 1st ed. CABI Publishing, Wallingford and New York, $578 \mathrm{pp}$.

BAKER M.R. 1978: Morphology and taxonomy of Rhabdias spp. (Nematoda: Rhabdiasidae) from reptiles and amphibians of southern Ontario. Can. J. Zool. 56: 2127-2141.

BAKER M.R. 1979: The free-living and parasitic development of Rhabdias spp. (Nematoda: Rhabdiasidae) in amphibians. Can. J. Zool. 57: 161-178.

BAKer M.R. 1987a: Synopsis of the Nematoda parasitic in amphibians and reptiles. Memorial University of Newfoundland, Canada. Occas. Pap. Biol., Gordon F. Bennett (Ed.), 11: 325 pp.

BAKer M.R. 1987b: Rhabdias collaris n. sp. (Nematoda: Rhabdiasidae) from frogs of Tanzania. Syst. Parasitol. 9: 199-201.

Ballantyne R.J. 1991: Life history and development of Pneumonema tiliquae (Nematoda: Rhabdiasidae). Int. J. Parasitol. 21: 521-533.

BAylis H.A. 1929: Some parasitic nematodes from the Uluguru and Usambara Mountains, Tanganyika Territory. Ann. Mag. Nat. Hist. 10: 372-381.

Bursey C.R., Goldberg S.R., Telford S.R. Jr. 2003: Rhabdias anolis n. sp. (Nematoda: Rhabdiasidae) from the lizard, Anolis frenatus (Sauria: Polychrotidae), from Panama. J. Parasitol. 89: 113-117.

Casiraghi M., Bain O., Guerrero R., Martin C., Pocacqua V., Gardner S.L., Franceschi A., Bandi C. 2004: Mapping the presence of Wolbachia pipientis on the phylogeny of filarial nematodes: evidence for symbiont loss during evolution. Int. J. Parasitol. 34: 191-203.

Chabaud A.G., Brygoo E.R., Petter A. 1961: Déscription et caractères biologiques de deux nouveaux Rhabdias malgaches. Ann. Parasitol. Hum. Comp. 36: 752-763.

Channing A., Howell K.M. 2006: Amphibians of East Africa. Cornell University Press, New York, 418 pp.

Chu T. 1936: Studies on the life history of Rhabdias fuscovenosa var. catanensis (Rizzo, 1902). J. Parasitol. 22: 140-160.

Durette-Desset M.-C., Baker J.R., Muller R. 1985: Trichostrongyloid nematodes and their vertebrate hosts: reconstruction of the phylogeny of a parasitic group. Adv. Parasitol. 24: 239-306.

Ferri E., Barbuto M., Bain O., Galimberti A., Uni S., Guerrero R., Ferté H., Bandi C., Martin C., Casiraghi M. 2009: Integrated taxonomy: traditional approach and DNA barcoding for the identification of filarioid worms and related parasites (Nematoda). Frontiers Zool. 6:1.

Folmer O., Black M., Hoeh W., Lutz R., Vrijenhoek R. 1994: DNA primers for amplification of mitochondrial cytochrome c oxidase subunit I from diverse metazoan invertebrates. Mol. Mar. Biol. Biotech. 3: 294-299.
Frost D.R. (Ed.) 2009: Amphibian Species of the World: an online reference. Version 5.3. Electronic Database accessible at http:// research.amnh.org/herpetology/amphibia/index.php. American Museum of Natural History, New York, USA, 2/2009.

Frost D.R., Grant T., Faivovich J.N., Bain R.H., Haas A., Haddad C.F.B., de Sá R.O., Channing A., Wilkinson M., Donnellan S.C., Raxworthy C.J., Campbell J.A., Blotto B.L., Moler P., Drewes R.C., Nussbaum R.A., Lynch J.D., Green D.M., Wheeler W.C. 2006: The amphibian tree of life. Bull. Am. Mus. Nat. Hist. 297: 1-370.

Goodey T. 1924a: Two new species of the nematode genus Rhabdias. J. Helminthol. 2: 203-208.

Goodey T. 1924b: The anatomy and life-history of the nematode Rhabdias fuscovenosa (Railliet) from the Grass Snake Tropidonotus natrix. J. Helminthol. 2: 51-64.

Guerrero R., Martin C., Gardner S.L., Bain O. 2002: New and known species of Litomosoides (Nematoda: Filarioidea): important adult and larval characters and taxonomic changes. Comp. Parasitol. 69: 177-195.

Hall T.A. 1999: BioEdit: a user-friendly biological sequence alignment editor and analysis program for Windows 95/98/NT. Nucleic Acids Symp. Ser. 41: 95-98.

Hartwich G. 1972: Über Rhabdias bufonis (Schrank, 1788) und die Abtrennung von Rhabdias dossei nov. spec. (Nematoda, Rhabdiasidae). Mitt. Zool. Mus. Berl. 48: 400-414.

KLoss G.R. 1971: Alguns Rhabdias (Nematoda) de Bufo no Brasil. Pap. Avul. Zool. 24: 1-52.

Küper W., Sommer J.H., Lovett J.C., Mutke J., Linder H.P., Beentje H.J., van Rompaey R.S.A.R., Cchatelain C., Sosef M., Barthlott W. 2004: Africa's hotspots of biodiversity redefined. Ann. Missouri Bot. Gard. 91: 525-535.

KuZmin Y.I. 1999: Rhabdias agkistrodontis (Nematoda: Rhabdiasidae): morphology, distribution and specificity. Folia Parasitol. 46: 59-66

Kuzmin Y.I. 2001: Rhabdias africanus sp. nov. (Nematoda, Rhabdiasidae), a new nematode species from the South African toads (Amphibia, Bufonidae). Acta Parasitol. 46: 148-150.

Kuzmin Y.I., Miskov R.O. 1999: On the life cycle of Rhabdias elaphe Sharpilo, 1976 (Nematoda, Rhabdiasidae). Acta Parasitol. 44: 119-124.

KuZmin Y., Tткасн V.V. (Eds.) 2009: Rhabdias. World Wide Web electronic publication, www.izan.kiev.ua/ppages/rhabdias, 4/2009.

Kuzmin Y., Tкасн V.V., Brooks D.R. 2007: Two new species of Rhabdias (Nematoda: Rhabdiasidae) from the marine toad, Bufo marinus (L.) (Lissamphibia: Anura: Bufonidae), in Central America. J. Parasitol. 93: 159-165.

KuZmin Y., TKach V.V., SNyder S.D. 2003: The nematode genus Rhabdias (Nematoda: Rhabdiasidae) from amphibians and reptiles of the Nearctic. Comp. Parasitol. 70: 101-114.

Letouzey R. 1985: Notice de la carte phytogeographique du Cameroun au 1:500,000 (Region Afro-montagnarde et étage sub- 
montagnard). IRA Yaoundé Cameroun/Inst. Carte Int. de la Végetation, Toulouse - France.

Lhermitte-Vallarino N., Bain O. 2004: Morphological and biological study of Rhabdias spp. (Nematoda) from African chameleons with description of a new species. Parasite 11: 15-31.

Lhermitte-Vallarino N., Bain O., Bertani S., Voza T., Attout T., Gaucher P. 2005: A new rhabdiasid nematode, Chabirenia cayennensis $\mathrm{n}$. g., n. sp., parasitic in the glands of the buccal mucosa of a South American saurian. Syst. Parasitol. 62: 151-160.

Lhermitte-Vallarino N., Barbuto M., Ineich I., Wanji S., LeBreton M., Chirio L., Bain O. 2008: First report of Rhabdias (Nematoda: Rhabdiasoidea) from lungs of montane chameleons in Cameroon: description of two new species and notes on biology. Parasite 15: 553-564.

Lhermitte-Vallarino N., Barbuto M., Junker K., Boistel R., IneICH I., WANJI S., Bain O. 2009a: Rhabdias rhampholeonis n. sp. and R. mariauxi n. sp. (Nematoda, Rhabdiasoidea), first lung worms from leaf chameleons: Description, molecular evidence and notes on biology. Parasitol. Int. 58: 375-383.

Lhermitte-Vallarino N., Junker K., Bain O. 2009b: Reappraisal of the specific status of Rhabdias (Nematoda) from Malagasy chameleons in the Paris Museum collection. Parasite 16: 111-123.

Linstow O. von 1903: Parasiten, meistens Helminthen, aus Siam. Arch. Mikrosk. Anat. 62: 108-121.

Lu S.C. 1934: On Rhabdias, a genus of parasitic Nematoda, of Nanking. Sinensia 5: 164-172.

Maley J. 1996: The African rainforest - main characteristics of changes in vegetation and climate from the Upper Cretaceous to the Quaternary. In: I.J. Alexander, M.D. Swaine and R. Watling (Eds.), Essays on the Ecology of the Guinea-Congo Rain Forest. Proc. R. Soc., Edinburgh 104B, pp. 31-73.

Martínez-Salazar E.A. 2008: A new rhabdiasid species from Craugastor occidentalis (Anura: Brachycephalidae) from Sierra Manantlán, Jalisco, Mexico. Rev. Mexico Biodiv. 79: 81-89.

Martínez-Salazar E.A., León-Règagnon V. 2007: New species of Rhabdias (Nematoda: Rhabdiasidae) from Bufo occidentalis (Anura: Bufonidae) from Sierra Madre del Sur, Mexico. J. Parasitol. 93: 1171-1177.

Received 27 September 2009
Moravec F., Baruš V., Ryšavý B. 1987: Some parasitic nematodes, excluding Heterakidae and Pharyngodonidae, from amphibians and reptiles in Egypt. Folia Parasitol. 34: 255-267.

Mucina L., Rutherford M.C. (Eds.) 2006: The Vegetation of South Africa, Lesotho and Swaziland. South African National Biodiversity Institute, Pretoria, 816 pp.

Passmore N.I., Carruthers V.C. 1979: South African frogs. Witwatersrand University Press, Johannesburg, pp. 68-73.

Runey W.M., Runey G.L., Lauter F.H. 1978: Gametogenesis and fertilization in Rhabdias ranae Walton 1929: I. The parasitic hermaphrodite. J. Parasitol. 64: 1008-1014.

Saad A.I., Khalifa R., Mostafa N. 2009: A lungworm nematode from amphibian hosts at Aswan Governorate, Egypt. World J. Zool. 4: 37-41.

Seurat L.G. 1920: Histoire Naturelle des Nématodes de la Bérbérie. Première Partie. Morphologie, Développement, Éthologie et Affinités des Nématodes. Université d'Alger, Faculté des Sciences, Fondation Joseph Azoubib, Trav. Lab. Zool. Gen. 221 pp.

Tamura K., Dudley J., Nei M., Kuma S. 2007: MEGA 4: Molecular Evolutionary Genetics Analysis (MEGA) software versions 4.0. Mol. Biol. Evol. 24: 1596-1599.

Thompson J.D., Gibson T.J., Plewniak F., Jeanmougin F., HigGINS D.G. 1997: The ClustalX Windows interface: flexible strategies for multiple sequence alignment aided by quality analysis tools. Nucleic Acids Res. 24: 4876-4882.

Tкасн V.V., Kuzmin Y., Pulis E.E. 2006: A new species of Rhabdias from lungs of the wood frog, Rana sylvatica, in North America: the last sibling of Rhabdias ranae? J. Parasitol. 92: 631-636.

Travassos L. 1926: Entwicklung des Rhabdias fülleborni n. sp. Arch. Schiffs Trop. Hyg. 30: 594-602.

Travassos L. 1930: Pesquizas helminthologicas realizadas em Hamburgo. VII. Notas sobre os Rhabdiasoidea Railliet, 1916 (Nematoda). Mem. Inst. Oswaldo Cruz 24: 161-181.

Vivien J. 1991: Faune du Cameroun: Guide des Mammifères et Poissons. Gicam, Yaoundé \& Min. Coop., Paris, 271 pp.

Yuen P.H. 1965: Some studies on the taxonomy and development of some rhabdiasoid and cosmocercoid nematodes from Malayan amphibians. Zool. Anz. 174: 276-298.

Accepted 15 December 2009 